DOI: $10.14451 / 1.170 .55$

\title{
ТЕХНОЛОГИЧЕСКИЕ И ЭКОНОМИЧЕСКИЕ ФАКТОРЫ ПОВЫШЕНИЯ ЭФФЕКТИВНОСТИ ЗАГОТОВИТЕЛЬНЫХ ПРОИЗВОДСТВ В МАШИНОСТРОЕНИИ РОССИИ
}

\author{
(C) 2019 Татарских Борис Яковлевич \\ доктор экономических наук, профессор \\ Самарский государственный экономический университет \\ 443090, Самара, ул. Советской Армии, д. 141 \\ E-mail: 999vv59@mail.ru
}

\section{(c) 2019 Федоров Олег Васильевич}

доктор технических наук, профессор

Нижегородский государственный технический университет им. Р.Е. Алексеева 603950, г. Нижний Новгород, ул. Минина, 24

В статье рассматриваются организационно-экономические и технологические проблемы реализации резервов ускорения развития заготовительных производств машиностроения. Показаны данные за последние 30 лет о структурных изменениях в заготовительных производствах. Обозначены возможные направления повышения эффективности заготовительных производств на основе использования достижений научно-технического прогресса.

Ключевые слова: машиностроение, заготовительные производства, факторы, структура, резервы, динамика, технологии, эффективность, тенденции.

Успешное функционирование машиностроения России во многом определяется динамикой потенциала заготовительных производств. Развитие заготовительных производств создает в машиностроении условия снижения материально-энергетических и трудовых затрат, позитивно влияет на динамику себестоимости производимой продукции. Повышение ресурсоотдачи - важнейший резерв роста инвестиционной привлекательности машиностроительных предприятий, что определяется прежде всего уровнем технологий на заготовительных стадиях производства. В комплексе заготовительных производств сложной инженерно-экономической проблемой является проблема снижения влияния негативных факторов энерготехнологической многоукладности и это относится к «стыкам» переделов, начиная с литейных цехов. В машиностроении за последние 30 лет в развитие материально-технической базы заготовительных производств вложено в 6-7 раз меньше инвестиций по сравнению с механообрабатывающими цехами. Сложная производственно-технологическая ситуация складывается в системе «металлургия-машиностроение», в которой традиционно очень медленно решаются технико-экономические задачи оптимизации заготовок. На большинстве предприятий комплекса не проводятся научные исследования тенденций структуры парка основного оборудования в заготовительных производствах и производствах обрабатывающих, что снижает результативность управления технологическим уровнем. В машиностроении плановая потребность в основном технологическом оборудовании обосновывается часто без привлечения ученых НИИ и ведущих технических вузов.

Специалисты отмечают, что в перспективе 20-25 лет основным конструкционным материалом останется металл. Доля металла будет составлять в общей массе не менее 45 процентов. Однако, под влиянием НТП, за этот период существенно изменится структура металлопотребления в связи с появлением технологичных заменителей металла. Дальнейшее применение в 2019-2024 гг. получат прогрессивные заменители металлов, в числе которых следует выделить пластические массы, керамику и так называемые композиты. Последние 30 лет продукция машиностроения страны отличается существенно от продукции передовых промышленно развитых стран (США, Япония, Германия, Ю. Корея) высоким уровнем металлоемкости. По отдельным видам производимой продукции этот уровень выше в 2,7-3,2 раза.

Машиностроители традиционно при опре- 
делении перспективной потребности в прогрессивных видах металлопродукции, как правило, ориентируются на сложившуюся структуру металлообрабатывающего оборудования и прежде всего на обработку металлов резанием, при которой коэффициент использования проката черных металлов остается низким практически во всех подотраслях отечественного машиностроения и составляет около 0,73 при 0,88 в США (данные 2016 года).

Значимым качественным показателем развития технологии является динамика структуры обрабатываемого металла в машиностроении, которая отражает основные методы воздействия орудия на предмет труда (табл. 1).

Научно-технический прогресс способствует применению новых марок стали особой прочности в ряде подотраслей машиностроения, но часто возникают технические сложности в использовании существующего парка металлообрабатывающего оборудования, что связано с несоответствием между стойкостью режущего инструмента, приспособлений и мощностью станков. Это характерно и для кузнечно-прессового и кузнечно-штамповочного оборудования, где энергетический фактор имеет особое значение. Дальнейшее развитие отечественного машиностроения предполагает непрерывное и значительное улучшение физических и механических свойств и увеличения сортамента проката. Сейчас потребность машиностроения в фасонных профилях и профилях специального назначения удовлетворяется в среднем не более чем на 60 процентов. В этой связи на практике используют профили другой формы или другого размера с последующей обработкой резанием, что ведет к значительным потерям металла. Сложное положение создалось с листовой сталью и прежде всего холоднокатаной. Вместо легких штампованных и сварных деталей используют отливки, а это увеличивает вес деталей и стоимость их примерно в 2 раза. Вместе с тем, несмотря на преимущество листоштампованных и сварных конструкций по сравнению с отливками, доля применения последних в серийном машиностроении страны значительно выше, например, чем в США. На практике в ряде случаев применение отливок экономически целесообразно, когда они получены прогрессивными методами. Однако, доля таких отливок, однако, составляет в машиностроении РФ не более тридцати процентов. В машиностроении России за последние годы медленно увеличивается доля применяемых прогрессивных заготовок (за исключением сварных металлоконструкций) (табл. 2).

Данные показывают, что в числе проблем повышения эффективности заготовительных производств в отечественном машиностроении особое значение имеет адресное материальное и моральное стимулирование экономии металла на всех уровнях производственной деятельности. Целесообразно при этом объективно оценить соответствующие параметры, по которым можно анализировать динамику коэффициента использования металла по основным технологическим пределам. В машиностроении за последние 35 лет динамика этого коэффициента очень незначительна и составляет всего 0,72 (при 0,71 в 1983 году). Наши данные показывают, что, коэффициент использования основных конструкционных материалов в машиностроении обработкой давлением за последние годы несколько повысился (табл. 3).

Следует отметить, что отечественном машиностроении не ведется системно анализ зависи-

Таблица 1. Динамика структуры металлопотребления,\% к итогу

\begin{tabular}{|l|c|c|c|c|c|c|}
\hline \multirow{2}{*}{ Вид производства } & \multicolumn{7}{c|}{ Годы } \\
\cline { 2 - 7 } & 1980 & 1990 & 2000 & 2010 & $\begin{array}{c}2018 \\
\text { оценка }\end{array}$ & $\begin{array}{c}2020 \\
\text { Прогноз }\end{array}$ \\
\hline Всего обработано металла & 100 & 100 & 100 & 100 & 100 & 100 \\
\hline $\begin{array}{l}\text { В том числе: } \\
\text { - в литейном производстве }\end{array}$ & $38-47$ & $36-45$ & $33-42$ & $31-40$ & $28-38$ & $29-34$ \\
\hline - в кузнечно-штамповочном производстве & $18-28$ & $20-30$ & $22-32$ & $24-34$ & $26-32$ & $27-33$ \\
\hline - в механическом производстве & $37-42$ & $30-40$ & $27-38$ & $28-36$ & $26-34$ & $24-35$ \\
\hline
\end{tabular}

По материалам отраслевых научно-технических журналов [1,2,3,4,5] 
Таблица 2.Динамика структуры заготовок в машиностроении,\% к итогу

\begin{tabular}{|l|c|c|c|c|c|c|c|c|c|}
\hline \multirow{2}{*}{\multicolumn{1}{|c|}{ Наименование }} & \multicolumn{7}{|c|}{ Годы } \\
\cline { 2 - 11 } & 1975 & 1980 & 1985 & 1990 & 1995 & 2000 & 2010 & $\begin{array}{c}2017 \\
\text { оценка }\end{array}$ & $\begin{array}{c}2020 \\
\text { прогно3 }\end{array}$ \\
\hline $\begin{array}{l}\text { Сварные металло- } \\
\text { конструкци }\end{array}$ & 48,3 & 50,0 & 51,2 & 51,6 & 51,9 & 53,0 & 55,0 & 60,0 & 63,0 \\
\hline Штамповки (горячие) & 8,0 & 8,2 & 8,0 & 7,9 & 7,9 & 7,5 & 7,0 & 6,0 & 5,0 \\
\hline Поковки из слитков & 2,1 & 2,0 & 2,0 & 2,0 & 1,9 & 1,5 & 1,5 & 1,2 & 1,2 \\
\hline Отливки & 41,6 & 39,7 & 38,8 & 38,6 & 38,2 & 38,0 & 39,0 & 37,0 & 36,0 \\
\hline В том числе: & 30,0 & 28,28 & 27,3 & 26,8 & 26,0 & 27,0 & 26,0 & 23,0 & 22,0 \\
\hline чугунные & 9,7 & 9,3 & 9,0 & 8,9 & 8,7 & 9,6 & 9,0 & 8,0 & 9,2 \\
\hline с цвальные & 1,9 & 2,07 & 2,2 & 2,5 & 2,9 & 3,4 & 4,0 & 4,9 & 4,8 \\
\hline
\end{tabular}

По материалам отраслевых научно-технических журналов [1,2,3,4,5]

Таблица 3. Динамика коэффициента использования материалов при изготовлении заготовок обработкой давлением в машиностроении

\begin{tabular}{|l|c|c|c|c|c|c|c|c|c|}
\hline \multicolumn{1}{|c|}{ Заготовки } & \multicolumn{7}{|c|}{ Годы } \\
\cline { 2 - 11 } & 1980 & 1985 & 1990 & 1995 & 2000 & 2005 & 2010 & $\begin{array}{c}2017 \\
\text { оценка }\end{array}$ & $\begin{array}{c}2020 \\
\text { прогноз }\end{array}$ \\
\hline $\begin{array}{l}\text { Поковки: } \\
\text { - из проката кованные; }\end{array}$ & 0,74 & 0,79 & 0,81 & 0,82 & 0,82 & 0,83 & 0,84 & 0,84 & 0,84 \\
\hline - из слитков кованные; & 0,65 & 0,65 & 0,66 & 0,67 & 0,68 & 0,68 & 0,69 & 0,70 & 0,71 \\
\hline - горяче-штампованные; & 0,76 & 0,78 & 0,79 & 0,80 & 0,80 & 0,81 & 0,82 & 0,84 & 0,84 \\
\hline $\begin{array}{l}\text { Заготовки: } \\
\text { - полученные холодной высадкой; }\end{array}$ & 0,90 & 0,91 & 0,91 & 0,91 & 0,91 & 0,92 & 0,93 & 0,93 & 0,93 \\
\hline $\begin{array}{l}\text { - полученные холодным } \\
\text { выдавливанием; }\end{array}$ & 0,92 & 0,93 & 0,93 & 0,93 & 0,94 & 0,94 & 0,94 & 0,95 & 0,95 \\
\hline $\begin{array}{l}\text { - полученные листовой штам- } \\
\text { повкой; }\end{array}$ & 0,75 & 0,76 & 0,76 & 0,77 & 0,78 & 0,79 & 0,79 & 0,81 & 0,84 \\
\hline - прессованные из пластмасс; & 0,91 & 0,92 & 0,92 & 0,92 & 0,93 & 0,93 & 0,94 & 0,95 & 0,95 \\
\hline $\begin{array}{l}\text { - из пластмасс, отлитые под } \\
\text { давлением; }\end{array}$ & 0,93 & 0,95 & 0,96 & 0,96 & 0,96 & 0,97 & 0,97 & 0,98 & 0,98 \\
\hline $\begin{array}{l}\text { - полученные прессованием метал- } \\
\text { лопорошков и твердых сплавов; }\end{array}$ & 0,90 & 0,92 & 0,92 & 0,92 & 0,93 & 0,93 & 0,93 & 0,94 & 0,95 \\
\hline
\end{tabular}

По материалам отраслевых научно-технических журналов [1,2,3,4,5]

мости между структурой металлопотребления и структурой основного металлообрабатывающего оборудования, что не обеспечивает оптимизацию материально-энергетических затрат, определяющих темпы себестоимости производимых машин и оборудования. Для повышения эффективности особое внимание следует уделять организационно-техническим проблемам экономии металла за счет конкретных меро- приятий на допроизводственной стадии современного машиностроительного производства учитывая постоянный рост цен на все основные виды металлопродукции применяемой в машиностроении страны.

В России заготовительные производства большинства предприятий машиностроения технологически значительно отстают от уровня по масштабам многих зарубежных стран про- 


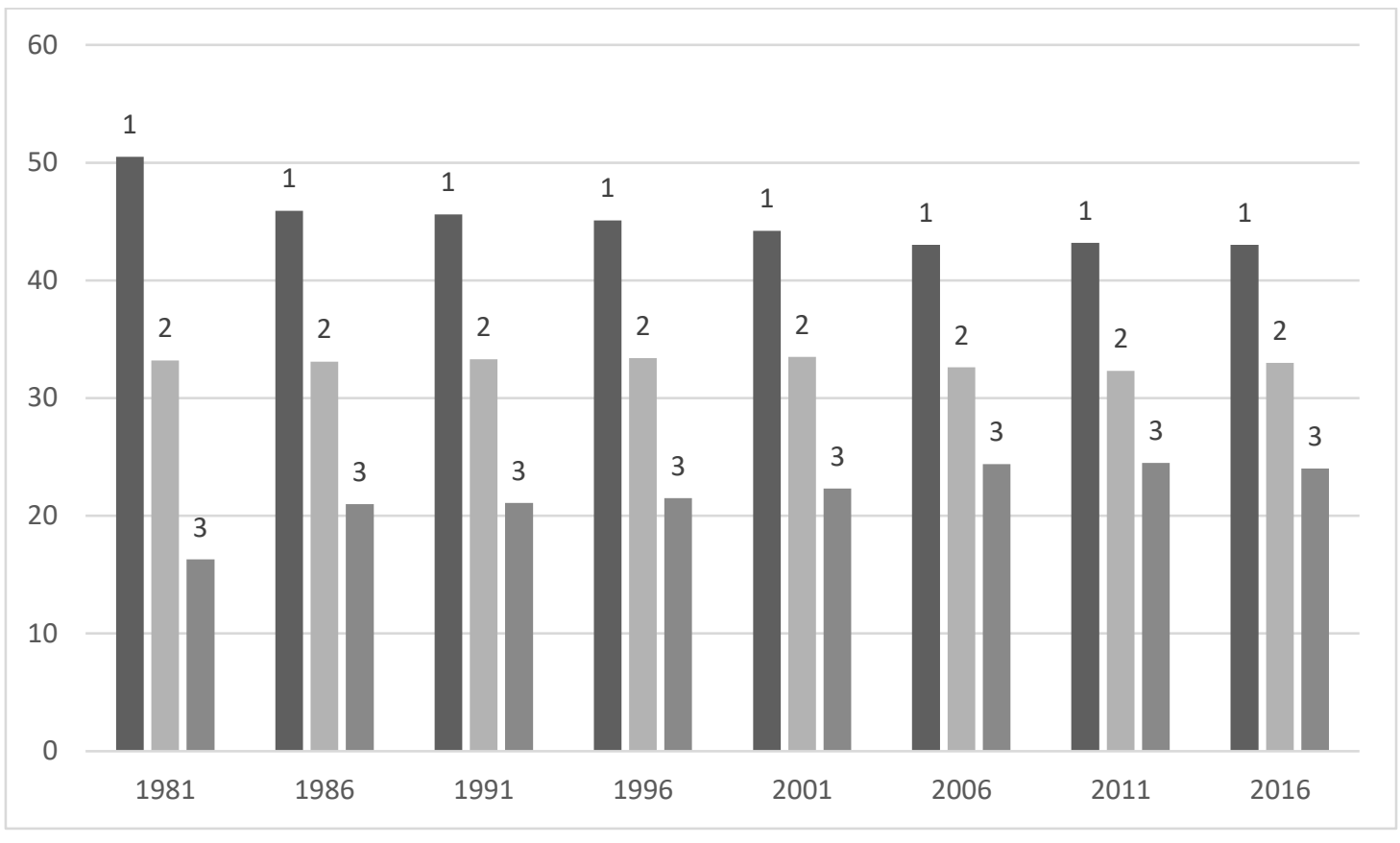

a - Металлорежущие станки, всего, в том числе в возрасте, лет

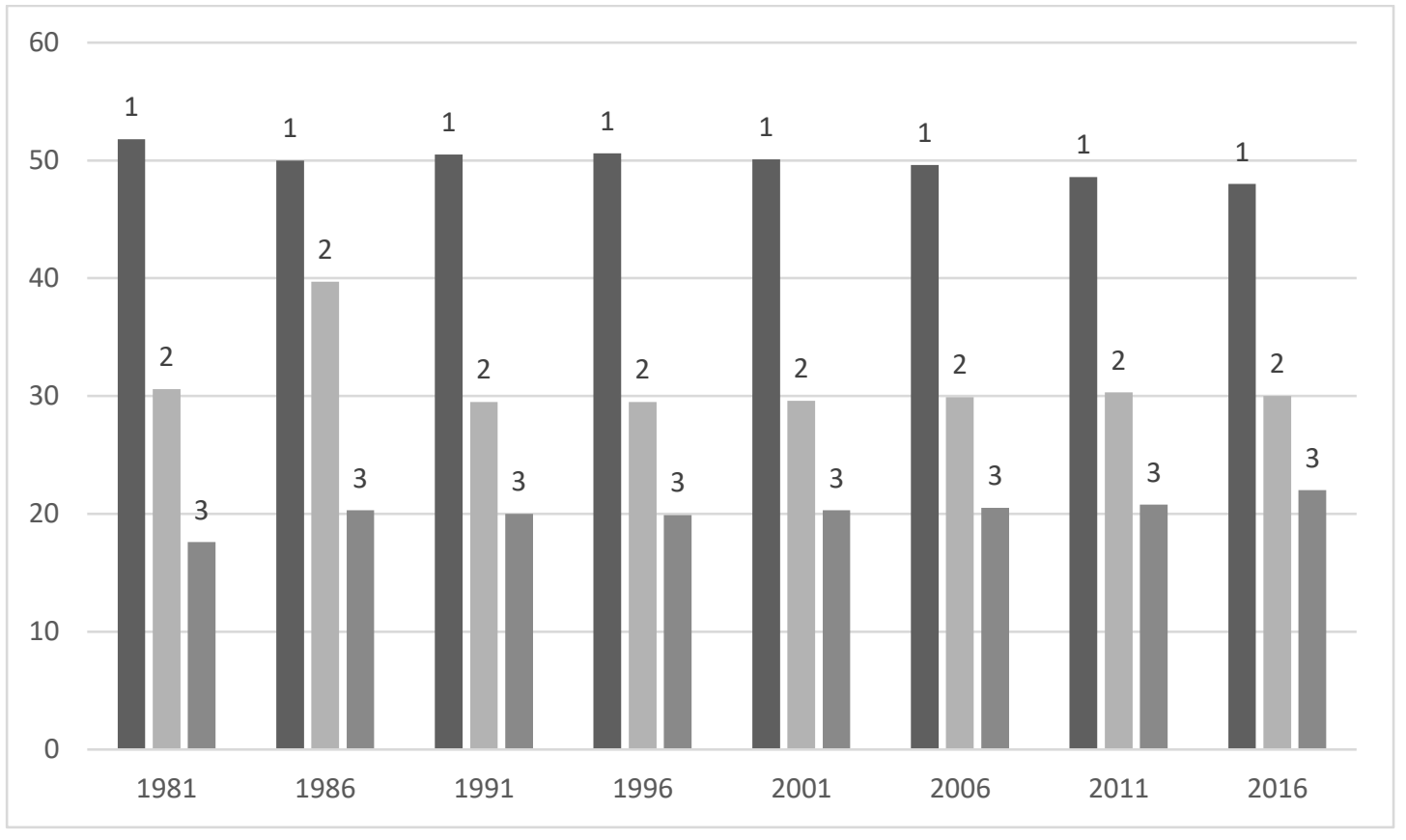

б - Кузнечно-прессовые машины всего, в том числе в возрасте, лет

Puc. 1. Динамика структуры парка металлообрабатывающего оборудования машиностроения (на конец года), \%

1 - до 10 лет; 2 - от 10 до 20 лет; 3 - свыше 20 лет

По материалам отраслевых научно-технических журналов $[1,2,3,4,5]$ 
изводства точных заготовок примерно в 3 раза. В машиностроении на развитие новых технологий в сфере производства прогрессивных материалов выделяется недостаточно инвестиций, что сказывается на качестве выпускаемой продукции. Установлено, что снижение технологического уровня производства прежде всего связано с ухудшением параметров основного оборудования и главным образом из-за морального и физического старения, когда ухудшаются базовые технико-экономические показатели оборудования (например, производительность, точность технологических операций, техническая надежность по критерию безотказной работы и т.д.). За последние 30 лет в машиностроении отмечается существенное старение парка ведущего технологического оборудования (рис. $1)$.

В отечественном машиностроении медленно решаются научно-методические вопросы прогнозирования производства и использования в машиностроении прогрессивных конструкционных и инструментальных материалов, как основных факторов ускорения развития базовых технологий в базовых переделах машиностроительного производства. При этом особое значение имеет «соединение» новых исходных конструкционных материалов и энергоносителей, обладающих высокими технико-экономическими показателями. Значительный экономический эффект может быть получен в заготовительных производствах металлургии, где есть современное металлообрабатывающее оборудование (например, кузнечно-штамповочные агрегаты мощностью 30 тыс. сило-тонн и пресса мощностью более 10 тыс. сило-тонн). Но показывают данные, потенциал таких уникальных агрегатов в отечественной промышленности используется недостаточно (их загрузка по времени составляет не более 20\%).

На основании сбора статистического материала по перспективным планом станкостроительных предприятий, можно ожидать, что к 2020 г. возрастная структура парка должна соответствовать:

a) по металлорежущим станкам: до 10 лет $41 \%$; от 10 до 20-38\%; свыше 20 лет - 21\%;

б) по кузнечно-прессовым машинам до 10 лет - 47\% от 10 до 20-33\%; свыше 20 лет - 20\%.

K основным причинам, которые привели к снижению эффективности заготовительных производств в машиностроении в 2003-2016 гг., прежде всего относят: низкий уровень системы управления научно-технологическим прогрессом; существенное разрушение организационно-экономического и научно-информационного пространства на межотраслевом и межрегиональном уровнях; отрицательные последствия приватизации, приведшей к значительной деформации научно-технической сферы; малоэффективная система механизмов привлечения иностранных инвестиций для внедрения инновационных технологий; очень медленное повышение потенциала технологий «двойного» назначения; критически высокий физический износ оборудования на предприятиях, производящих наукоемкую продукцию; отсутствие четкой стратегии подготовки инженерных кадров для наукоемких подотраслей машиностроения; низкая результативность инновационного менеджмента; нарушение сроков выполнения государственных программ внедрения новых технологий; устаревшие формы и методы стимулирования применения прогрессивных технологий в заготовительных производствах.

Дальнейшее развитие заготовительных производств - важный фактор повышения эффективности отечественного машиностроения.

\section{Библиографический список}

1. Виньков А. Машиностроение: пустая поляна // Эксперт.2018. № 33. С. 51.

2. Композит - ЭКСПО 2017. Обзор.//Машиностроитель. 2017. № 5. С. 52-53.

3. Татарских Б.Я. Организационно-экономические вопросы развития заготовительных производств в машиностроении // Заготовительные производства в машиностроении. 2007. № 2. С. 3-8.

4. Татарских Б.Я. Экономические вопросы использования в машиностроении достижений научно-технологического прогресса// Вестник экономики и менеджмента. 2016. Вып.2. С. 74-76.

5. Яровая Е.И. Эффективность управления литейными технологическими процессами/ Е.И. Яровая, И. О. Леушин, М.М. Спасская, М.А. Ларин // Черные металлы. 2018. № 3. С.29-33 